NASA TECHNICAL MEMORANDUM 104141

\title{
PREDICTION OF MATRIX FATIGUE CRACK INITIATION IN NOTCHED SCS-6/Ti-15-3 METAL MATRIX COMPOSITES
}

B. M. Hillberry and W. S. Johnson

\section{OCTOBER 1991}

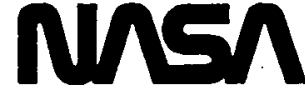

National Aeronautics and

Space Administration

Langley Research Center Hampton, Virginia 23665

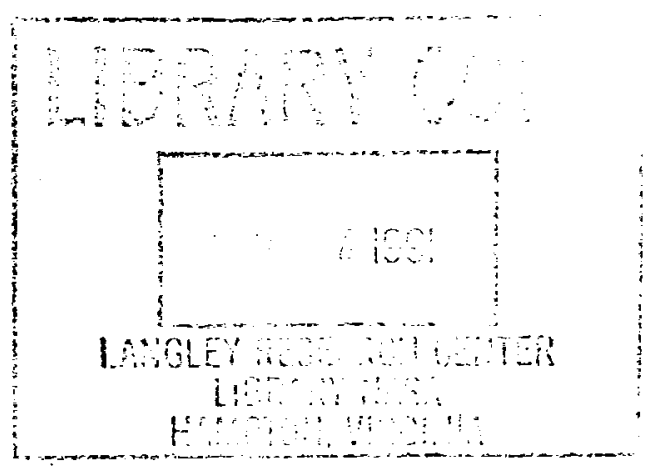




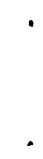




\title{
PREDICTION OF MATRIX FATIGUE CRACK INITIATION IN NOTCHED \\ SCS-6/Ti-15-3 METAL MATRIX COMPOSITES
}

\author{
by \\ B. M. Hillberry ${ }^{*}$ and W. S. Johnson. ${ }^{* *}$ \\ NASA Langley Research Center \\ Materials Division \\ Hampton, VA 23665-5225
}

Several lay-ups of SCS-6/Ti-15-3 metal matrix composites were tested in either a center hole or a double edge notched geometry. At different cyclic stress levels the number of cycles required to develop matrix fatigue cracks at the notches was recorded. A fatigue strain-life curve was developed for the Ti-15-3 matrix material. The Smith, Watson, Topper effective strain parameter was modified to account for local stress concentration at the notch tip and thermal residual stresses in the matrix material. This modified parameter predicted the number of cycles required for matrix crack initiation at the notches. The predictions were in good agreement with the experimental data.

KEYWORDS: Effective strain, residual thermal stress, stress concentration

* Professor, School of Mechanical Engineering, Purdue University ( study conducted while a Senior NRC Research Associate on leave from Purdue University.)

** Senior Research Scientist. 


\section{INTRODUCTION}

Fatigue behavior of metal matrix composites (MMC) at room temperature, as well as elevated temperature, is of particular interest in advanced aerospace applications. MMC's

offer high stiffness at relative low weight along with good elevated temperature properties. The metal matrix can carry a significant portion of the composite's load. Cracking of the matrix material can cause a global reduction in composite properties. Further, load can be shed by the cracked matrix and redistributed into the load carrying fibers causing premature failure. It is, therefore, important to be able to predict the onset of matrix fatigue damage, in particular, at a notch tip.

Johnson, et al. [1] have studied the fatigue behavior of continuous fiber SCS-6/Ti-15-3 for a variety of laminates and loading conditions. Tensile loading of a $[90]_{8}$ cross-ply laminate showed a knee in the laminate stress - strain curve at a stress level well below matrix yield. This knee was caused by the failure of the fiber-matrix interface due to tensile stresses acting normal to the interface. The fiber-matrix separation was verified using replicas of the specimen edge taken while under load. The knee in the stress - strain curve was also observed upon unloading, indicating that the matrix was closing around the fiber due to matrix thermal residual stresses. The thermal residual stresses developed during the fabrication process were accurately predicted using a concentric cylinder model [1].

In room temperature fatigue tests of unnotched specimens, Johnson [2] also observed that at higher applied loads, the fibers failed before matrix fatigue cracks developed. At lower loads and longer life $(50,000$ cycles plus), the matrix material fatigue cracks prior to fiber failure. In these tests, the off-axis plies lost stiffness due to the fiber-matrix separation as described above. Johnson et al. [1] showed good correlation of fatigue life with the zero degree fiber stress, which 
is the composite stabilized strain range (after fiber-matrix separation) multiplied by the fiber modulus. This correlation is shown in Figure 1 for a variety of lay-ups and loading levels for specimens in the as-fabricated condition.

In contrast to the unnotched specimens Naik and Johnson [3] observed that matrix fatigue cracks initiated next to the notches (double edge notched and center hole) and grew across fibers without failing the fibers. Figure 2 shows the uniform matrix fatigue crack pattern observed in the center hole specimen. Harmon et al. [4] observed similar fatigue crack patterns in center hole specimens. Hillberry and Johnson [5] showed that the crack spacing could be predicted using cylindrical shear lag models.

The objective of this paper is to present an approach, based upon effective strain, to predict the number of fatigue cycles required to initiate a fatigue crack in the matrix material at the notch tip in a metal matrix composite of arbitrary lay-up utilizing cyclic strain to failure data from unnotched matrix specimens. We will specifically examine SCS-6/Ti-15-3 composites containing either center holes or edge notches.

\section{EXPERIMENTAL PROCEDURES}

\section{Materials and Specimens}

The material system tested in this study was SCS-6/Ti-15-3 continuous fiber composite, the same as that tested by Johnson et al. [1] and Naik and Johnson [3]. The material properties [1] are listed in Table 1. The fiber volume fraction was 0.325 and the lay-up tested was $[0 / 90]_{2 \mathrm{~s}}$ in the as-fabricated condition. The composites were tested in both the center hole $(\mathrm{CH})$ and double edge notched (DEN) geometries. The center hole specimen was $19 \mathrm{~mm}$ wide by 1.78 
$\mathrm{mm}$ thick with a $6.35 \mathrm{~mm}$ diameter hole. The stress concentration factors $\mathrm{K}_{\mathrm{t}}$ for the $\mathrm{CH}$ specimens (shown in Table 1) were calculated using orthotropic laminate equations developed by Harmon et al. [4]. The double edge notch specimen was $19 \mathrm{~mm}$ wide with a $0.2 \mathrm{~mm}$ by 3 $\mathrm{mm}$ deep notch electro-discharge machined on each side. The values of $\mathrm{K}_{\mathrm{t}}$ for the DEN specimens (shown in Table 1) were calculated using a two-dimensional finite element analysis.

Room temperature fatigue tests were also run on the 'Ti-15-3 matrix material in the as-fabricated condition. This material was prepared from Ti-15-3 foil sheets processed the same as the composite laminate except no fibers were inserted between the foils during consolidation. The matrix specimens were dog bone shape with a width and thickness of 11.53 $\mathrm{mm}$ and $1.62 \mathrm{~mm}$, respectively.

\section{Testing Techniques}

For this study, fatigue tests were run on center hole and double edge notched specimens of $[0 / 90]_{2 s}$ laminates. The specimen configurations and test conditions, 0.1 stress ratio and $10 \mathrm{~Hz}$ frequency, were identical to those used by Naik and Johnson [3]. Some tests were repeated for this study to monitor the fatigue crack patterns. The CH specimen was tested under constant amplitude loading at a maximum applied stress of $150 \mathrm{MP}$ a. The DEN specimen was tested under constant amplitude loading at a maximum applied stress of 197 MP. Tests were conducted at a stress ratio of 0.1 . All specimens were polished and monitored visually using a microscope and periodic surface replicas to observe crack initiation and growth. Fatigue crack initiation was defined to occur when a crack length of (0.2-(0.4 $\mathrm{mm}$ could be observed.

Fatigue tests of the matrix materials were run at a strain ratio of 0.1 and at $10 \mathrm{~Hz}$ under strain control. The load-strain hysteresis loops were monitored periodically throughout the tests. Failure in these tests was specimen fracture. 


\section{DEVELOPMENT OF A LOCAL EFFECTIVE STRAIN CRITERION}

The modulus of the SCS- 6 fibers is more than four times that of the titanium matrix, which results in the fibers carrying most of the total composite load. Any cyclic softening or hardening that may occur in the matrix during fatigue will cause only a very small change in the overall composite modulus even in the vicinity of a notch. As a result, since the fibers remain elastic, the matrix is exposed to a strain-controlled load condition in which the strain is proportional to the applied stress. This also means that the stress and strain concentrations affecting the matrix will be the same and equal to the elastic stress concentration factor.

The objective of the present work is to predict matrix crack initiation for the composite from fatigue life data for the matrix material alone. The stress ratio effects, geometric stress concentration and thermal residual stresses caused by the differences in the coefficients of thermal expansion the fiber and the matrix during cool down from consolidation temperature must be accounted for.

Since the matrix is assumed to be subjected to a strain-controlled loading condition, the strain concentration factor is essentially equal to the elastic stress concentration factor. The strain range at the notch tip is therefore $\mathrm{K}_{\mathrm{t}} \Delta \epsilon$.

The stress ratio effects can be accounted for by the Smith, Watson and Topper (SWT) effective strain parameter [6]. This parameter, shown to account for stress ratio for a variety of isotropic materials under a variety of loading conditions, is defined as 


$$
\Delta \epsilon \text { eff }=(\epsilon \max \Delta \epsilon / 2)^{1 / 2}
$$

where $\Delta \epsilon=$ applied strain range

$\epsilon_{\max }=$ maximum applied strain.

Harmon et al. [4] used the SWT effective strain parameter to predict crack initiation in aluminum matrix composites using a laminate level approach.

We have modified the SWT parameter to obtain an effective strain parameter at a notch that includes the strain concentration and the thermal residual stress $\left(\sigma_{r}\right)$ in the matrix due to fabrication. The maximum strain next to the notch can be written as

$$
\text { Maximum local strain }=\mathrm{K}_{\mathrm{t}} \max _{\max }+\sigma_{\mathrm{r}} / \mathrm{E}
$$

$$
\begin{aligned}
& \text { where } \epsilon_{\max }=\text { maximum nominal value of applied strain } \\
& \qquad \mathrm{E}=\text { Young's modulus of the matrix material. }
\end{aligned}
$$

The strain range at the notch is $\mathrm{K}_{\mathrm{t}} \Delta \epsilon$ and effective strain parameter for the notched composite becomes

$$
\Delta \epsilon \text { eff }=\left[\left(K_{\mathrm{t}} \epsilon \max +\sigma_{\mathrm{r}} / \mathrm{E}\right) \mathrm{K}_{\mathrm{t}} \Delta \epsilon / 2\right]^{1 / 2}
$$

This assumes that the matrix remains essentially elastic throughout the applied cyclic loading and, therefore, the stress and strain concentrations are the same. 
The matrix thermal residual stress in the fiber axial direction due to cooling during manufacture was calculated by Johnson et al. [1] to be $207 \mathrm{MPa}$. This value of axial thermal residual stress is representative of both unidirectional and $[0 / 90]_{2 s}$ lay-ups.

For a notched composite with thermal residual stresses, the matrix fatigue life can be predicted by comparing the effective strain from Eq. (3) with the SWT effective strain versus fatigue life curve for the matrix material calculated using Eq. (1).

\section{RESULTS AND DISCUSSION}

In the strain-controlled matrix fatigue tests, the cyclic load-strain hysteresis loops were stable throughout and the ratio of plastic strain to elastic strain was very small $(<0.02)$ even at the higher strain levels. The small ratio of plastic to elastic strain indicates that the fatigue is predominantly controlled by the elastic strain component. The strain range versus life for the matrix material is shown in Figure 3 plotted as a function of the SWT effective strain parameter, Eq. (1).

The observed and predicted lives until crack initiation for the notched specimens are presented in Table 2. The predicted life was determined from Figure 3 using the calculated value of the effective strain for the given specimen geometry and loading, Eq. (3). These predicted and observed values are also compared in Figure 4 where the solid line is the SWT matrix curve from Figure 3. The cyclic strain at the notch in conjunction with the SWT effective strain provides a good prediction of the number of cycles required for fatigue crack initiation in notched SCS-6/TI-15-3 where the prediction is based on the matrix fatigue life curve. 
From Table 2 one can see the required cyclic stress levels for crack initiation. The unnotched strength of $[0 / 90]_{2 \mathrm{~s}}$ is $945 \mathrm{MPa}$ [1] while the cyclic stress level required for crack initiation at a center hole in 60,000 cycles is $150 \mathrm{MPa}$. For the $[0]_{8}$ double edge notched specimen, a crack initiated at 25,000 cycles at a maximum stress level of $122 \mathrm{MPa}$. Since the unnotched strength of the [0] laminate is $1518 \mathrm{MPa}$ [1] the matrix cracked at a cyclic stress that was only $8 \%$ of the unnotched strength. This implies that only a very small percentage of the composite's strength can be used if fatigue damage is to be avoided under cyclic loading conditions. Johnson [2] has shown that this type of matrix fatigue cracking can lower a $[0 / 90]_{2 s}$ composite's notch strength by as much as $40 \%$. Therefore, the fatigue behavior of the matrix material is a very important consideration when screening or designing new MMC materials.

\section{CONCLUDING REMARKS}

Several lay-ups of SCS-6/Ti-15-3 metal matrix composites were tested in either a center hole and double edge notched geometry. The number of cycles required to initiate and grow a crack of approximately $0.2-0.4 \mathrm{~mm}$ in length from the notch was recorded for a variety of loading amplitudes and laminates. A fatigue S-N curve was developed for the Ti-15-3 matrix material. The Smith, Watson, Topper effective strain parameter was modified to account for local stress concentrations at the notch tip and thermal residual stresses in the matrix material. This modified parameter predicted of the number of cycles required for matrix crack initiation at the

notches. The predictions were in good agreement with the experimental data. The analysis and experimental data showed that matrix fatigue damage initiated at a stress level that was a low percentage of the composite unnotched static strength. Since such matrix fatigue cracking can significantly lower the strength of notched composites, this cracking must be well understood and addressed in the design of any man-rated vehicle. 


\section{REFERENCES}

[1] Johnson, W.S., Lubowinski, S.J. and Highsmith, A.L., "Mechanical Characterization of Unnotched SCS-6/Ti-15-3 Metal Matrix Composites at Room Temperature," Thermal and Mechanical Behavior of Ceramic and Metal Matrix Composites, ASTM STP 1080, Kennedy, Mouller, and Johnson, Eds., Am. Soc. Test. Mat., 1990, pp. 193-218.

[2] Johnson, W. S., "Fatigue of Continuous Fiber Reinforced Titanium Metal Matrix Composites," Mechanical Fatigue of Advance Materials, Ritchie, Cox, and Dauskardt, Eds., MCEP publishers, 1991.

[3] Naik, R.A., and Johnson, W.S., "Observations of Fatigue Crack Initiation and Damage Growth in Notched Titanium Matrix Composites," Third Symposium on Composite Materials: Fatigue and Fracture, ASTM STP 1110, T. K. O'Brien, Ed., Am. Soc. Test. Mat.,1991.

[4] Harmon, D.M., Saff, C.R. and Sun, C.T., "Durability of Continuous Fiber Reinforced Metal Matrix Composites," AFWAL-TR-87-3060, Wright-Patterson Air Force Base, Ohio, October 1987.

[5] Hillberry, B.M. and Johnson, W.S., "Matrix Fatigue Crack Development in a Notched Continuous Fiber SCS-6/Ti-15-3 Composite," Micro-cracking Induced Damage in Composites, Ed. Dvorak and Lagoudas, American Society of Mechanical Engineering, AMD-Vol. 111, MD-Vol. 22, pp. 121-127, 1990.

[6] Smith, K.N., Watson, R. and Topper, T.H., "A Stress-Strain Function for the Fatigue of Metals," Journal of Materials, Vol. 5, No. 4, pp. 767-778, 1970. 
Table 1. SCS-6/Ti-15-3 Properties [1]

As-fabricated condition

Fiber Modulus:

Fiber Poisson's ratio:

Matrix Modulus:

Matrix Poisson's ratio:

Matrix Yield:

Matrix Ultimate:

Fiber Diameter:

Fiber volume fraction:
$400 \mathrm{GPa}$

0.25

$92.4 \mathrm{GPa}$

0.35

$690 \mathrm{GPa}$

$934 \mathrm{GPa}$

$0.142 \mathrm{~mm}$

0.325

Table 2. Predicted and observed cycles to initiation.

\begin{tabular}{|c|c|c|c|c|c|c|}
\hline $\begin{array}{l}\text { Specimen } \\
\text { Geometry }\end{array}$ & Layup & $\begin{array}{l}S_{\max } \\
\text { Applied }\end{array}$ & $K_{t}$ & $\begin{array}{l}\text { Predicted } \\
\text { No. Cyles } \\
\end{array}$ & $\begin{array}{l}\text { Observed } \\
\text { Ne. Cycles? }\end{array}$ & Ref. \\
\hline $\mathrm{CH}$ & {$[0 / 90]_{2 \mathrm{~s}}$} & $150 \mathrm{MPa}$ & 3.6 & 33,000 & 60,000 & Present work \\
\hline DEN & {$[0 / 90]_{2 s}$} & $197 \mathrm{MPa}$ & 5.5 & 3,400 & 3,000 & Present work \\
\hline DEN & {$[0]_{8}$} & $122 \mathrm{MPa}$ & 6.6 & 30,000 & 25,000 & 3 \\
\hline DEN & {$[0] 8$} & $250 \mathrm{MPa}$ & 6.6 & 3,400 & 7,500 & 3 \\
\hline $\mathrm{CH}$ & {$[0 / 90 / 0]$} & $215 \mathrm{MPa}$ & 3.6 & 29,000 & 50,000 & 3 \\
\hline $\mathrm{CH}$ & {$[0 / 90]_{2 s}$} & $137 \mathrm{MPa}$ & 3.6 & 43,000 & $51,000^{3}$ & 3 \\
\hline
\end{tabular}

1) $\mathrm{CH}=$ Center hole specimen, $\mathrm{DEN}=$ Double edge notch specimen

2) First observed crack was $0.2-0.4 \mathrm{~mm}$.

3) Tested for 50,000 cycles at $137 \mathrm{MPa}$ followed by 1000 cycles at $150 \mathrm{MPa}$. At $137 \mathrm{MPa}$, failure was predicted at 43,000 cycles. 


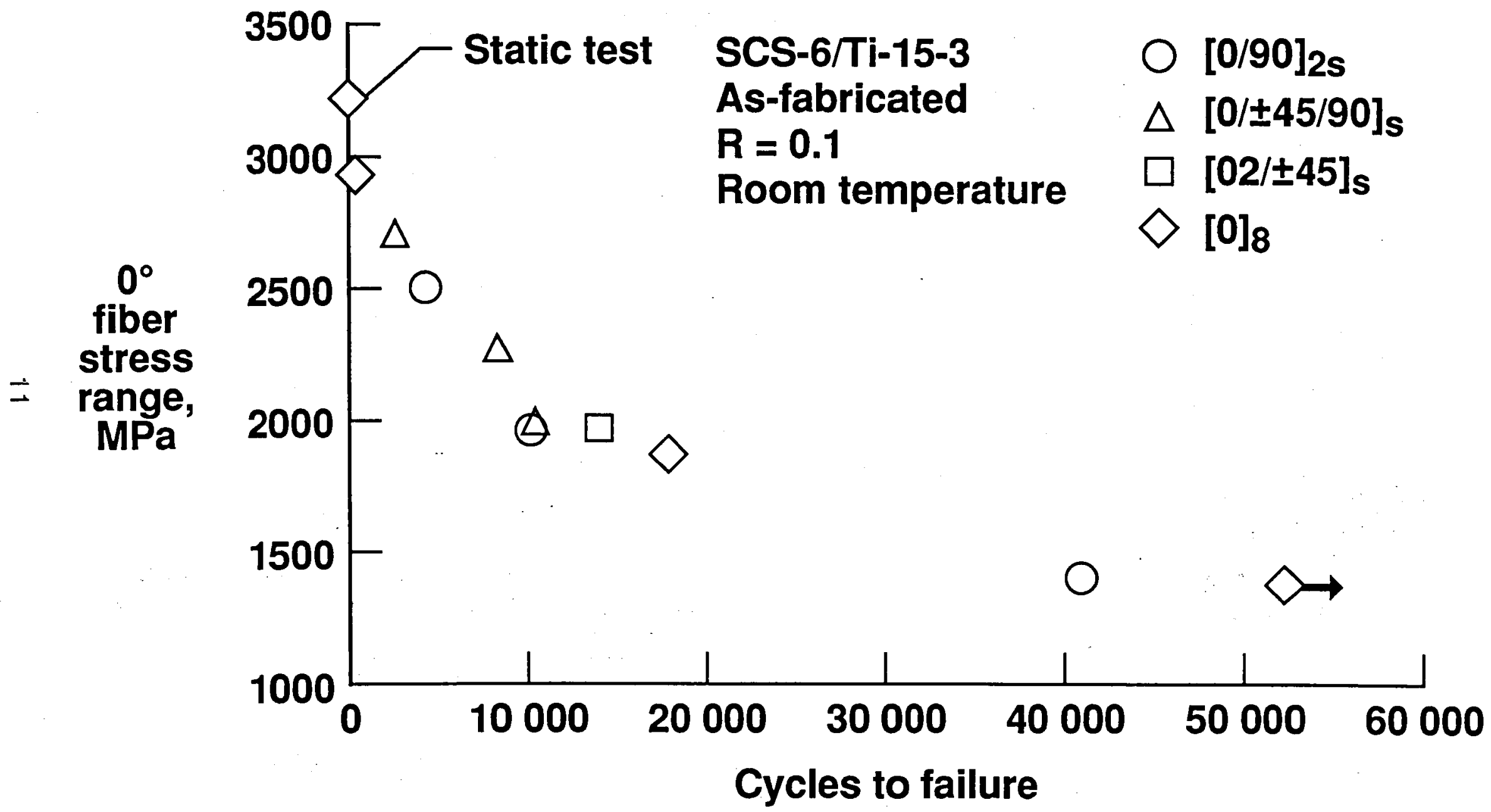

Figure 1. Cyclic stress range in $0^{\circ}$ fiber versus number of cycles to laminate failure for unnotched specimens (1). 
SCS-6/Ti-15-3

$[0 / 90]_{2 s}$

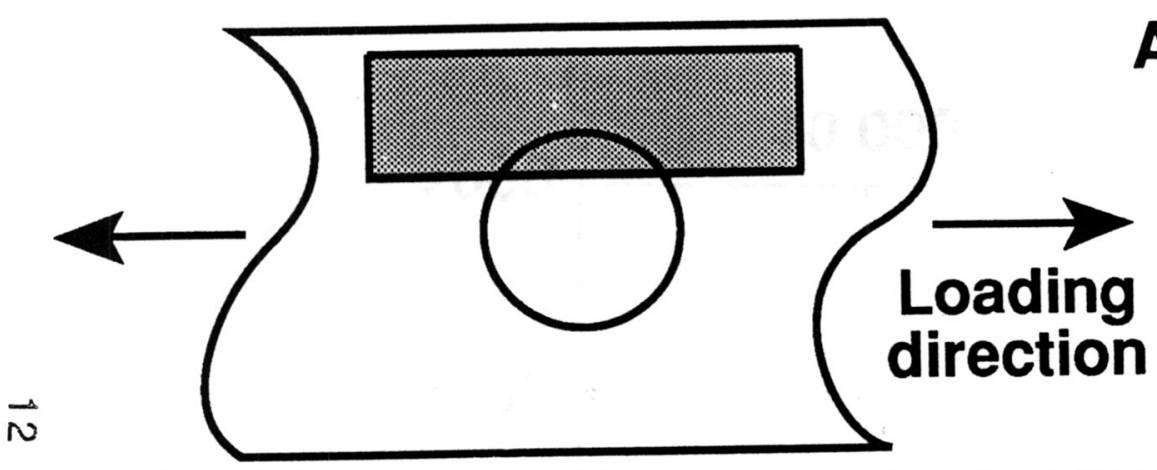

Max. stress = $150 \mathrm{MPa}$ 50,000 cycles $\mathbf{R}=0.1$

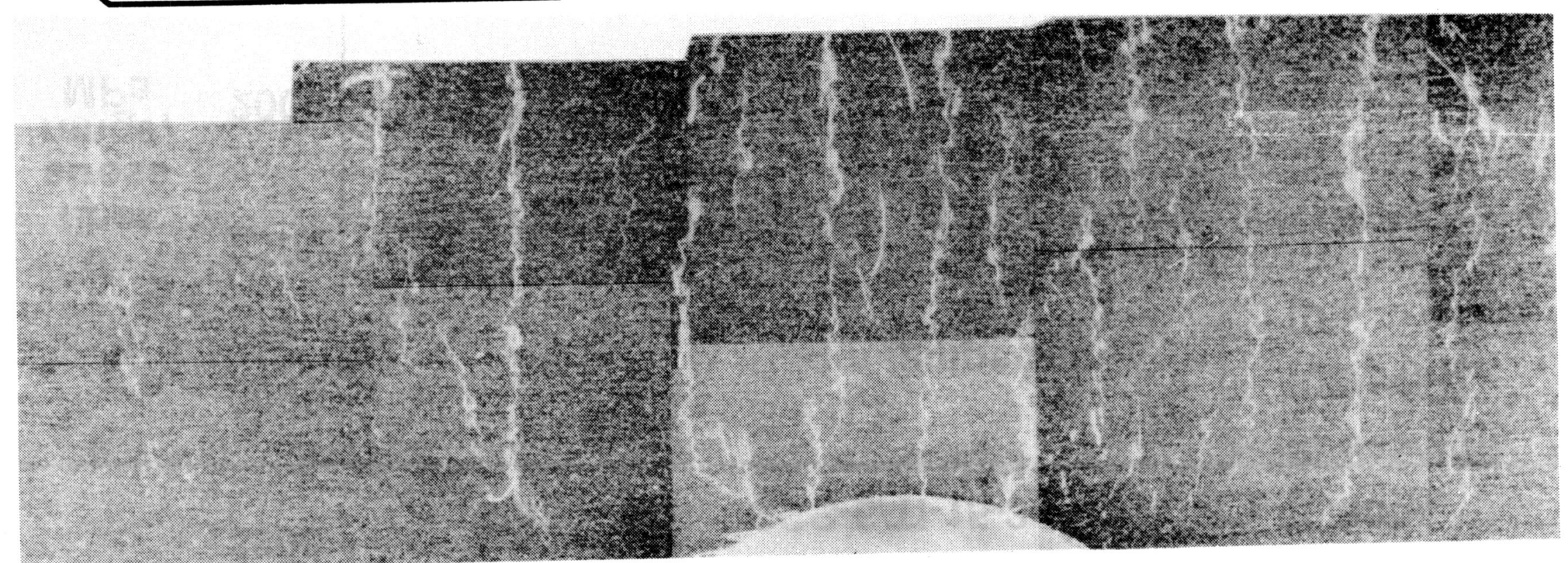

Figure 2. Surface matrix fatigue crack for a center hole $[0 / 90] 2 \mathrm{~s}$ specimen (3). 


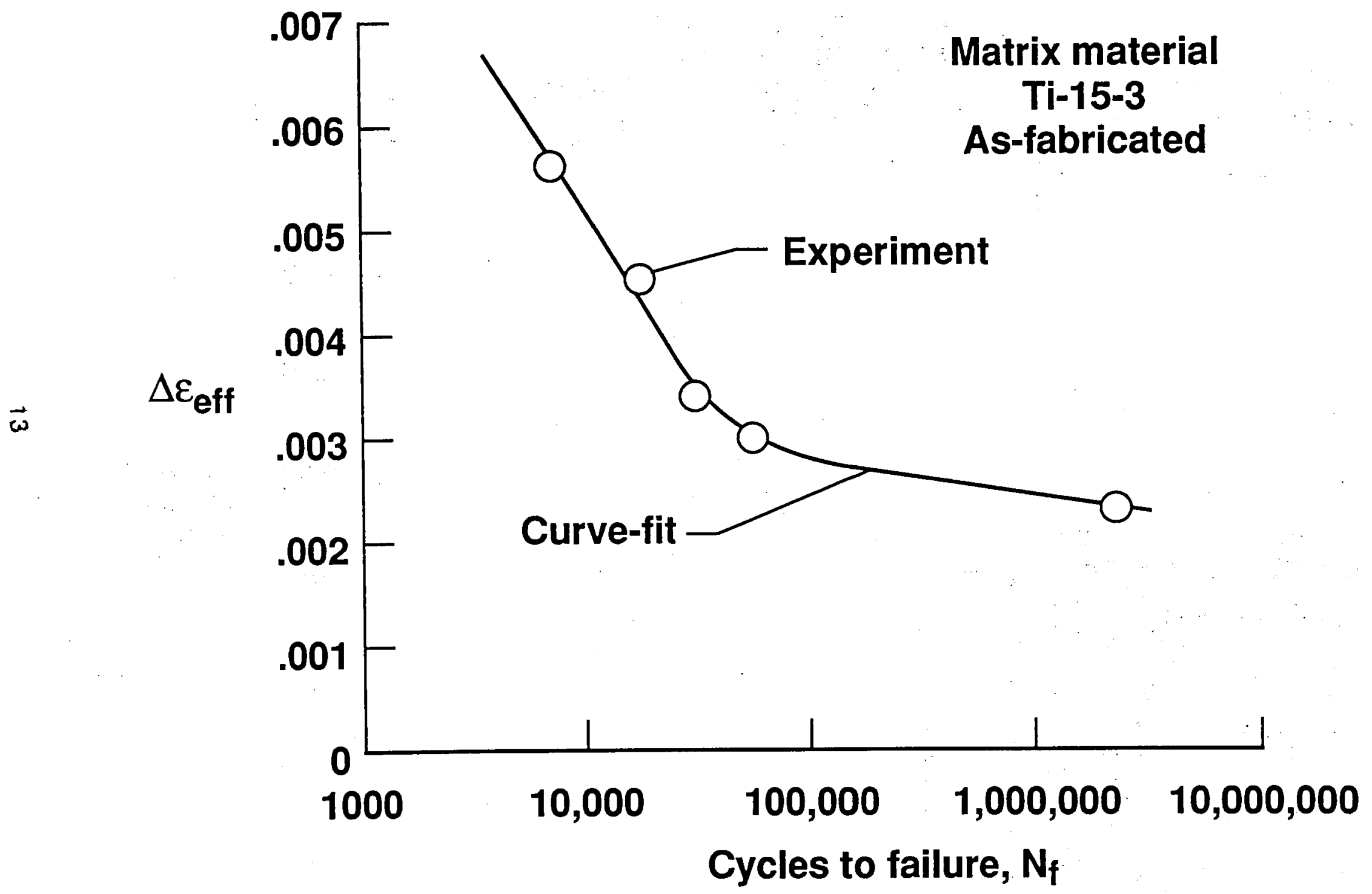

Figure 3. Smith, Watson, Topper effective strain parameter versus fatigue life for the as-fabricated matrix material. 


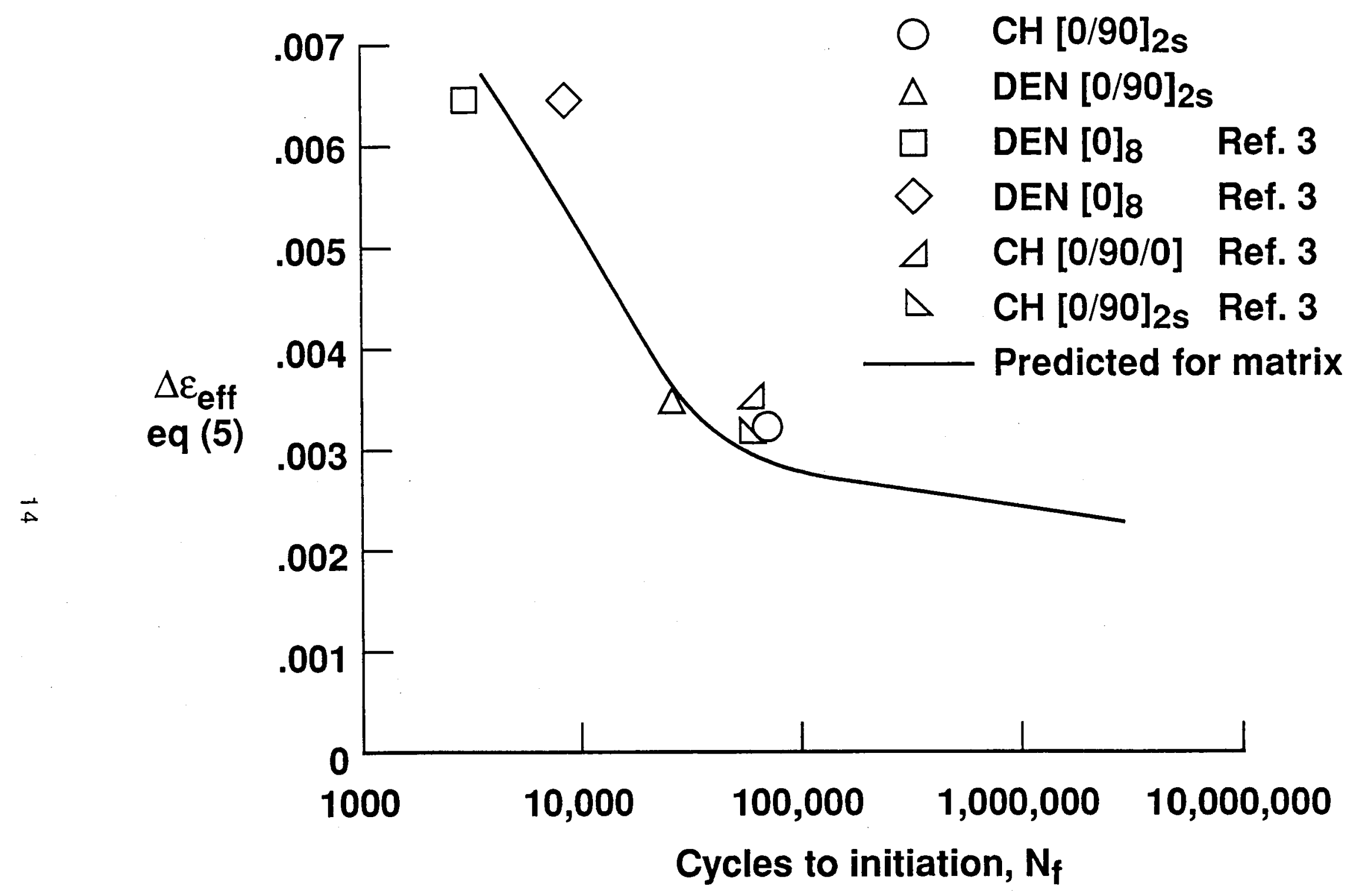

Figure 4. Predicted versus experimental crack inititation. 
- 


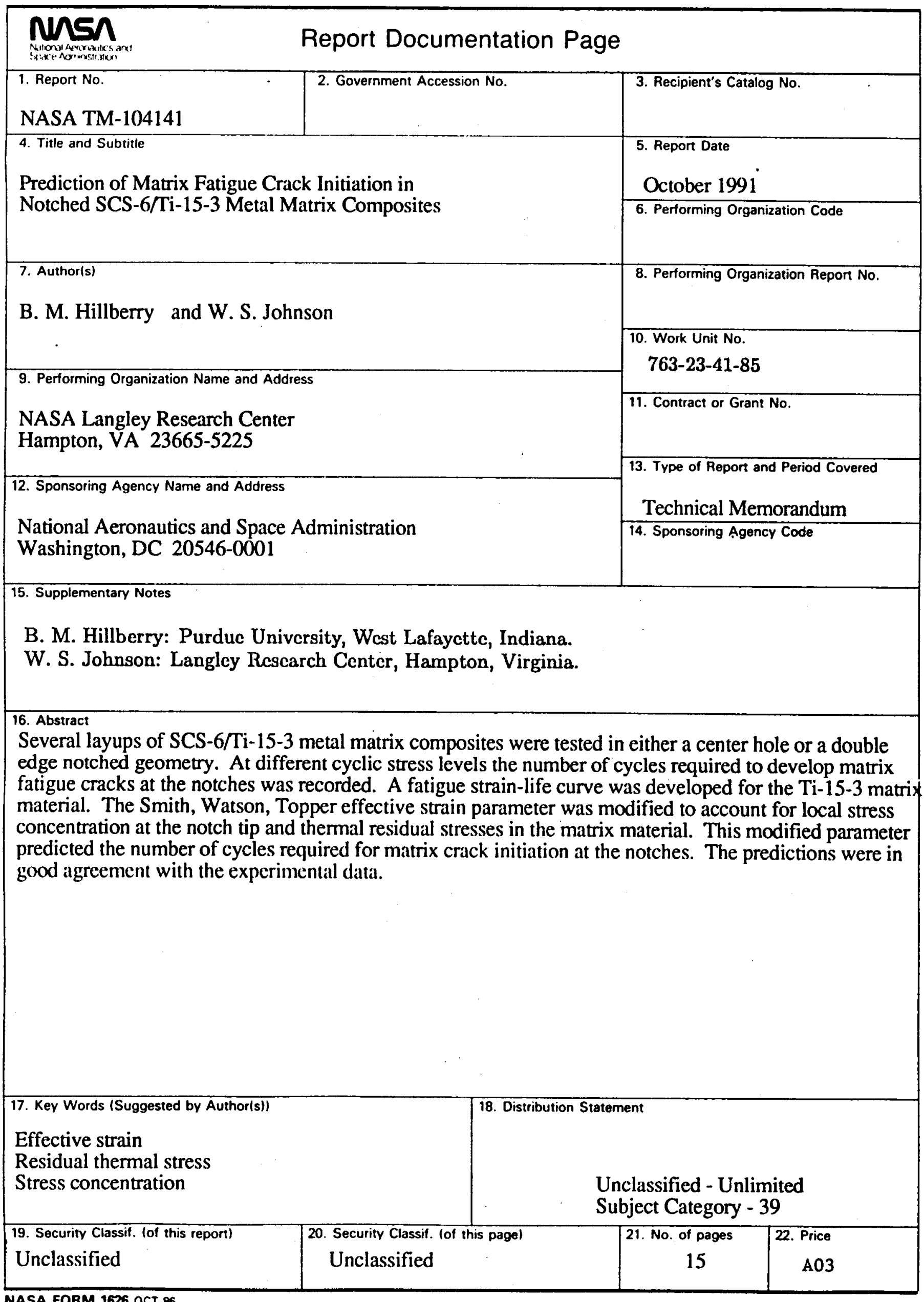




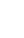




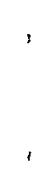

